\title{
Understanding the link between maternal adult attachment classifications and thoughts and feelings about emotions
}

\author{
CAREY ANNE DEOLIVEIRA ${ }^{1}$, GREG MORAN ${ }^{2}$, \& DAVID R. PEDERSON ${ }^{2}$ \\ ${ }^{1}$ Child and Parent Resource Institute, Ontario, Canada, and ${ }^{2}$ University of Western Ontario, Canada
}

\begin{abstract}
The purpose of this study was to examine the associations between maternal representations of attachment, as assessed with the Adult Attachment Interview (AAI; George, Kaplan, \& Main, 1996), and mothers' thoughts and feelings about their own emotions and emotions emerging in their toddlers. Eighty-nine adolescent mothers completed the AAI and the Center for Epidemiological Studies Depression Scale (CES-D; Radloff, 1977) and Katz, Gottman, Shapiro, and Carrere's (1997) metaemotion interview for parents of toddlers. Autonomous mothers demonstrated the most open and flexible mindset around a variety of emotions in themselves and their toddlers. Dismissing mothers exhibited a tendency to minimize internalizing emotions in themselves and their children, while unresolved mothers described the most emotion regulatory difficulties.
\end{abstract}

Keywords: Attachment, emotion socialization, emotion regulation, attachment representations, adolescent mothers

\section{Introduction}

Emotional experiences are central to the development of attachment relationships. In fact, effective dyadic regulation of affect in infancy is arguably a defining feature of the secure attachment relationship (Sroufe, 1996). There is ample evidence that secure and insecure attachment relationships are associated with distinctive patterns of infant and toddler affective behavior and experience (Goldberg, 2000; Grossmann, Grossmann, \& Schwan, 1986; Spangler \& Grossmann, 1993; Thompson, Flood, \& Lundquist, 1995), differences that can be viewed as assisting children in meeting their attachment-related needs (Cassidy, 1994). Indeed, mothers of secure, avoidant, and resistant children may reinforce these distinctive patterns of emotional expression (Berlin \& Cassidy, 2003; Goldberg, MacKaySoroka, \& Rochester, 1994).

\section{Maternal AAI classifications and emotion}

It has also been suggested that maternal representations of attachment are linked to specific emotional strategies and consequent socialization patterns (Cassidy, 1994). Haft and Slade (1989) have argued that a mother's internal working model helps her organize, interpret, and sometimes distort or avoid, emotionally tinged attachment-relevant information in a

Correspondence: Dr. Carey Anne DeOliveira, Child and Parent Resource Institute, 600 Sanatorium Rd, London, Ontario, Canada. Tel: (519) 8582774(2387).E-mail: CareyAnne.DeOliveira@css.gov.on.ca 
manner that allows her to preserve her state of mind with respect to attachment. There has been little empirical evaluation of this proposed link.

George, Kaplan, and Main's (1996) Adult Attachment Interview (AAI) assesses adult attachment representations by asking participants to describe and reflect on their childhood relationships with their own parents. In the AAI, an autonomous mother is able to discuss her own childhood experiences in a reflective, coherent, and emotionally flexible manner, free from distortions and emotional defenses (Main, 2000; Main \& Goldwyn, 1998). We would expect these mothers in their daily lives to be aware and accepting of a range of emotions and able to express and regulate their emotions appropriately. Dismissing mothers, on the other hand, restrict or ignore negative affect in the AAI (Cassidy, 1994), perhaps reflecting childhood experiences where "defensive exclusion" (Bowlby 1969/1982) was the most effective reaction to stressful situations. This deactivating emotional strategy would lead such mothers to detach from interactions that might trigger negative feelings (Magai, 1999). Consistent with this suggestion, Kobak and Sceery (1988) found that dismissing individuals saw themselves as having more distant relationships and less social support than autonomous individuals, although they did not report distress about their life situation. A study by Adam, Gunnar, and Tanaka (2004), however, found feelings of joylessness, fatigue, disinterest, and disengagement among dismissing mothers. Other research has linked dismissing representations to elevated levels of anxiety and depression associated with externalizing symptoms, for example avoidance symptoms of anxiety rather than fear symptoms (Dozier, Stovall, \& Albus, 1999). Indeed, several studies have found that dismissing representations are more likely to be linked with externalizing as opposed to internalizing mental health and relational problems (Allen, Hauser, \& Borman-Spurrell, 1996; Kobak \& Sceery, 1988; Riggs \& Jacobvitz, 2002).

In contrast, preoccupied individuals seem involved and entangled in their own attachment experiences, with AAI transcripts flooded with passivity, anger, and distress (Main \& Goldwyn, 1998). These individuals appear to exhibit a hyperactivating coping strategy and a "fight" response in which negative affect is amplified (Magai, 1999). Again, it has been suggested that this strategy originates in early experiences where a heightened focus on attachment-relevant emotions promotes physical and psychological closeness (Cassidy, 1994). Unfortunately, this strategy may increase a vulnerability to being overwhelmed by negative affect in situations of significant stress or sadness. Numerous studies have linked preoccupied representations with decreased ego-resiliency and increased vulnerability to emotional disturbances (Adam et al., 2004; Dozier et al., 1999; Kobak \& Sceery, 1988; Riggs \& Jacobvitz, 2002).

Individuals classified as unresolved in the AAI are disoriented in their discussion of loss or abuse as indicated by lapses in monitoring reasoning or discourse (Hesse \& Main, 2000; Main \& Hesse, 1990); their emotion regulatory strategies reflect a lack of resolution of these life events (Jacobvitz, Hazen, \& Riggs, 1997; Main \& Hesse, 1990). This parental attachment classification is linked with infant attachment disorganization (see van IJzendoorn, 1995, for a review) and to signs of failure to monitor behavior in infant-parent interactions (Madigan, Moran, \& Pederson, in press; Schuengel, Bakermans-Kranenburg, van IJzendoorn, \& Blom, 1999; True, Pisani, \& Oumar, 2001). Main and Hesse (Hesse \& Main, 2000; Main \& Hesse, 1990) propose that emotional dysregulation, especially around fear, is the source of these lapses in monitoring in both discourse and interaction. The unresolved attachment classification is related to various indices of emotional dysregulation (Creasey, 2002) and is highly over represented in samples of patients displaying borderline personality disorder and those suffering severe anxiety and depression (Dozier et al., 1999; Fonagy et al., 1996). Thus, while the approaches to emotions adopted by dismissing and preoccupied mothers may reflect organized strategies for regulating emotions, unresolved mothers appear to lack a 
functional strategy for coping with intense emotional experiences, leaving them more vulnerable to emotional dysregulation.

\section{Maternal AAI classifications and perceptions of toddler emotions}

Such differences in maternal affective mindsets have significant implications for a mother's perception, interpretation, and response to her child's affect. Cassidy's (1994) suggestion that a dismissing mother must minimize her infant's attachment-relevant negative emotions in service of her own coping strategy is supported by evidence that these mothers sometimes respond to indications of infant negative affect in a defensively distorted or inhibiting way (Haft \& Slade, 1989; Zeanah, Beniot, Barton, Regan, Hirshberg, \& Lipsett, 1993). Dismissing mothers, however, in a manner parallel with the externalization of their own emotions, may well be aware of and involved in their child's externalized negative affect (i.e., anger) at the same time as they are avoidant of internalized affect. Using their assessment of a mother's representation of her relationship with her child, the Parent Development Interview (PDI; Aber, Belsky, Slade, \& Crinic, 1999; Slade, Belsky, Aber, \& Phelps, 1999), Slade and colleagues (1999) found that dismissing mothers scored highest on the anger dimension of the PDI and autonomous mothers scored highest on the joy-pleasure, coherence dimension.

In contrast to the style proposed for a dismissing mother, a preoccupied mother's predisposition to maximize relational affect should extend to caregiving (Cassidy, 1994; George \& Solomon, 1999). She may be reluctant to help her child with emotion regulation because she interprets displays of attachment-related affect as signs of her child's dependency. Her child's attachment-related affect might also jeopardize her own tenuous emotion regulation capacities (Haft \& Slade, 1989). In either case, preoccupied mothers would be expected to be overly embroiled in their child's negative affect and to perceive these emotions as dysregulated or overwhelming, and be unlikely to respond effectively to relieve such distress.

Unresolved mothers, because of their own emotional dysregulation, would likely be most negatively affected by their children's emotional signals. Lyons-Ruth and her colleagues suggest that unresolved mothers project alarming or contradictory messages because they are compelled to protect themselves from their own overwhelming fear as they struggle to respond to their infants' distress (Lyons-Ruth, Bronfman \& Atwood, 1999). The infant's affect may serve as a trigger for maternal re-experiencing of her own emotional trauma, thus eliciting atypical or frightening behaviors (Jacobvitz et al., 1997; Lyons-Ruth et al., 1999; Main \& Hesse, 1990). Lyons-Ruth and colleagues have argued that such lapses in interaction should be seen as illustrative of a broader inability to provide her child with the essential affect regulatory assistance or to "repair" disruptions (Lyons-Ruth et al., 1999; Solomon \& George, 1999).

\section{Assessment of the maternal affective mindset}

Katz, Gottman, Shapiro, and Carrere's (1997) Meta-Emotion Interview provides a useful vehicle for examining these proposed characteristic affective mindsets of mothers with different representations of attachment. The Meta-Emotion Interview asks mothers directly to reflect on their own and their toddler's emotions. The content of their responses is explicitly coded. Parents have the opportunity to describe their philosophies, attitudes, and strategies pertaining to their own emotional experiences (fear, anger, and sadness) as well as the emotions that are emerging in their children. Responses are used to reflect participants' awareness, acceptance, and regulation of their own emotions and their awareness, acceptance, and coaching of emotions in their toddlers. Research indicates that parental 
"meta-emotion philosophy" (authors' terminology) is related to positive parenting and children's ability to regulate emotions. Hooven, Gottman, \& Katz (1995) found that parental awareness of their own sadness and "coaching" of child anger were related to more positive parent-child interaction and functional child outcomes. In accordance with the objectives of the current study, Cowan (1996) has suggested that exploring the links between the AAI and the meta-emotion interview could contribute importantly to our understanding of emotion socialization processes and "...may provide a framework for attachment researchers who are seeking to explain the correlations among adult attachment, parenting styles, and children's developmental outcomes" (Cowan, 1996, p. 281).

\section{The current study}

The current study examines the inter-relations of maternal representations of attachment (as assessed in the AAI) affective mindset (assessed by the meta-emotion interview), depression (assessed by the CES-D), and self-reported responsiveness to their children's emotions (assessed by the meta-emotion interview) in a group of young mothers. This population was chosen because adolescent mothers are more likely to have experienced troubled and sometimes-traumatic family histories, including physical and sexual abuse (Cassidy, Zoccolillo, \& Hughes, 1996). This sample also is more likely to include a higher proportion of non-autonomous attachment representations (Ward \& Carlson, 1995) and mothers facing a wider range of emotional challenges and associated emotional styles than a nonclinical, middle class sample (Cassidy et al., 1996). Thus, the sample choice not only is aimed at shedding light on an important aspect of parenting in a population at developmental risk but also promises to provide a broader range of affective styles, responsiveness, and attachment representations than likely to be found in other populations.

We explore a series of hypotheses regarding the associations of maternal attachment representations and a mother's distinctive affective mindset as revealed by her reactions and attitudes toward her own and her toddler's emotions. Specifically, we hypothesize that: autonomous mothers will demonstrate the most flexible mindset about emotions, where emotions are validated but not perceived as overwhelming; dismissing mothers will exhibit a deactivating attitude toward emotions, wherein they express a lack of awareness and acceptance of their emotional experiences, externalize symptoms of depression, and report a lack of responsiveness to their child's internalized affect; preoccupied mothers will be more likely to describe a hypervigilance to their own and their children's emotional experiences, with associated difficulties in emotion regulation; and, finally, mothers classified as unresolved will describe emotional experiences as overwhelming and dysregulating and will have greater propensity for depression.

Confirmation of these associations would lend support to the proposal that the emotion socialization process itself is central to the transmission of attachment styles from one generation to the next (van IJzendoorn, 1995).

\section{Method}

\section{Participants}

The participants in the present study were children and their mothers recruited into a longitudinal intervention study during their postpartum stay in the hospital. All infants were full term gestation and physically healthy at birth. Participating mothers met the following criteria: less than 20 years of age, medically uneventful delivery, and full term birth without 
complications. By the end of the recruitment process, 100 dyads were involved in the study and were initially seen when the infants were 6 months of age. Of these, 90 dyads (46 girls, 44 boys) remained in the study through the 24-month visit and comprise the sample considered in all analyses reported here.

Demographic information was obtained during a home visit when the infants were 6 months of age. Approximately $81 \%$ of the sample was Caucasian. The remaining mothers were of Native American $(n=5)$, Middle Eastern $(n=5)$, Latin American $(n=4)$, Caribbean $(n=1)$, and Asian $(n=1)$ descent. Fifty-seven percent were single/never married, $28 \%$ were living common law, and $15 \%$ were married. Mean maternal age at the time of the infant's birth was 18.42 (SD 1.01) with a range from 15.97 to 19.98 . Annual personal and family income was recorded on a scale from 1 to 8 , with 1 signifying "less than $\$ 5,000$ " and 8 , "more than $\$ 60,000 "$. The average personal income approximately corresponded to 2 , "between $\$ 5,000$ and $\$ 9,999 "$. Average household income was only slightly higher, corresponding to approximately 3 , “between $\$ 10,000$ and $\$ 19,999$ ". The majority of the sample $(80 \%)$ reported being unemployed or working as a full time student at the time this data were collected. According to Statistics Canada's Low Income Cut-Offs the poverty cut-off line for a single mother with one child living in a city the size of London is $\$ 20,200$ /year (Statistics Canada, 2001).

\section{Overview of procedure}

During a home visit when the infants were around 6 months of age, mothers completed the AAI (George, Kaplan, \& Main, 1996) and CES-D (Radloff, 1977). When the children were approximately 2 years of age, mothers were interviewed with the meta-emotion interview for parents of toddlers (Katz, Gottman, Shapiro, \& Carrere, 1997).

Of the 90 mothers in the present sample, 46 dyads were randomly assigned to the intervention group and 44 served as comparison subjects. The intervention model was a structured behavioral model focused on enhancing maternal behavioral sensitivity. Mothers were videotaped interacting with their infants and then reviewed the tapes with the home visitors using a strength-based interaction guidance approach. (Clark \& Seifer, 1983; Krupka, 1995).

\section{Measures}

Adult Attachment Interview. The AAI (George, Kaplan \& Main, 1996) included questions asking the mother to reflect on her experiences with attachment figures, early childhood and her perceptions of her parents at that time, experiences of early emotional and physical upsets, possible abuse and deaths of loved ones, including her reactions and those of her parents to these events. Transcripts were coded according to Main and Goldwyn's (1998) coding system. Each of the young mothers was assigned a primary classification for their state of mind with respect to attachment based on their discourse style in the interview. The three primary attachment classifications were autonomous, dismissing, and preoccupied. Autonomous individuals responded to questions about their childhood in a consistent, relevant and coherent manner. Dismissing mothers often idealized or failed to recall their childhood experiences and appear oblivious to clear contradictions in their stories. Preoccupied adults, on the other hand, typically expressed confusion, passivity, anger, and distress when speaking about their attachment figures; their interviews often were incoherent and difficult to follow. In addition to the three primary classifications (autonomous, dismissing, and preoccupied), individuals may have been classified as unresolved with 
respect to trauma and/or loss. Unresolved individuals sometimes become disorganized when they discuss potentially traumatic past experiences or experiences of loss and exhibit lapses in monitoring of reasoning or discourse during the interview (Main \& Goldwyn, 1998).

Thirty-five of the 82 AAI transcripts were independently scored by two experienced coders (trained by M. Main and E. Hesse) who had passed the reliability test for the AAI. The percentage concordance between the two coders for the four classifications (Ds, F, E, $\mathrm{U} / \mathrm{d}$ ) was $86 \%$, kappa $=.78, p<.001$.

\section{Centre for Epidemiological Studies Depression Scale}

The CES-D (Radloff, 1977) is a 20-item self-report measure designed for use in a general population. This scale is a state measure intended to measure current levels of depressive symptoms. The CES-D demonstrates discriminant validity beyond clinician's ratings and other self-report scales, is generalizable across subgroups, and displays internal consistency when used with general samples and with samples of adolescent and young adult females (alphas .82-.89, Radloff, 1977). Because the CES-D is a state measure, only moderate test - retest reliability was expected. Previous research found increases in CES-D scores to be related to negative life events (Radloff, 1977). Eighty-nine of the 90 mothers in the current study completed and returned the questionnaire.

Recall that Dozier and colleagues (1999) suggested that dismissing mothers might display externalizing (e.g., somatic complaints, irritability) rather than internalizing, emotionfocused symptoms (e.g., reports of feeling sad and lonely) symptoms of depression. To assist in effectively elucidating these different dimensions of depressive symptomatology, six clinical psychology doctoral students were asked to sort the twenty CES-D items into two categories: an affective-internalizing category (focusing on one's internal thoughts and feelings) and a somatic-externalizing category (focusing on external factors or physical/ somatic concerns or symptoms). Thirteen of the items were sorted into the first category and the remaining seven fell into the second category (by majority consensus). The 13 items in the affective-internalizing category were: I was bothered by things that usually don't bother me, I felt that I could not shake off the blues even with the help from my family and friends, I felt that I was just as good as other people (reverse coded;-), I felt depressed, I felt hopeful about the future (-), I thought my life had been a failure, I felt fearful, I was happy ( - ), I felt lonely, I enjoyed life (-), I had crying spells, I felt sad, I felt that people disliked me. The seven items that fell into the somatic-externalizing category were: I did not feel like eating; my appetite was poor, I had trouble keeping my mind on what I was doing, I felt that everything I did was an effort, my sleep was restless, I talked less than usual, people were unfriendly, I could not "get going". Individual scores for the two scales were calculated by averaging the individual response across the items (accounting for items that were reverse coded). The two scales were correlated, $r=.59$, $p<.001$. Cronbach's alpha coefficient for the affective-internalizing subscale was 0.77 , and 0.76 for the somatic-externalizing category.

\section{Meta-emotion interview for parents of toddlers}

This revised version of the original Meta-Emotion Interview (Katz \& Gottman, 1986) was completed during a 24-month home visit (Katz et al., 1997). The focus was on emotionbased executive functions of emotion (Hooven et al., 1995), on awareness of one's own emotion, awareness and acceptance of child emotions, and on coaching of child emotions. Participants were asked quite general questions about their past and current experiences of fear, sadness, and anger; philosophy of emotional expression and control; and attitudes and 
behavior towards their children's fear, anger, and sadness ${ }^{1}$. The entire interview was audiotaped and then coded directly from the tape using the comprehensive Meta-Emotion Coding System (Hooven, 1994).

Each emotion (sadness, anger, and fear) was coded on seven dimensions, three reflecting a mother's own emotions (awareness, acceptance, and regulation) and four regarding her responses to her child's emotion (awareness, acceptance, coaching, and perception of toddler's regulation). Each dimension was made up of several subscales coded on a 5-point scale. Some of the subscales under the awareness domain included "parent experiences this emotion," "parent provides a descriptive anecdote". Some of the subscales under the coaching domain were "parent shows respect for child's experience of emotion," "when child is upset, parent talks about situation, emotion".

The coder could also choose to code "don't know" for any of the subscales. This would occur when insufficient information was provided from the mother's narrative. The number of don't knows were tallied for later analyses, as interviewers noted that the number of don't knows was generally inversely related to the mother's openness and/or engagement in discussion of emotions.

Adequate reliability and predictive and discriminant validity of the Meta-Emotion Coding System has been reported in several sources (Gottman, Katz, \& Hooven, 1996; Hooven et al., 1995; Katz \& Windecker-Nelson, 2001). The meta-emotion variables have been found to be associated with parent - child interaction, child anxiety, child physiological measures of stress, child behavior problems, peer interactions, marital satisfaction, and academic achievement.

Two trained coders who had not been trained in the AAI system coded the Meta-Emotion Interviews independently from the AAI. Four interviews were used in the initial stages of gaining familiarity with the measure and any discrepancies/disagreements were conferenced to a single agreed-upon score used in the data analysis. The remaining of the interviews were coded by one of the two coders, both of whom were blind to other information about the dyads. In addition, both individuals coded 25 randomly selected tapes for the purposes of establishing interrater reliability. With the exception of the Mother's Perception of Child Regulation scale, acceptable interrater reliability was achieved for each scale within each emotion category. With respect to the emotion fear, interrater reliability on maternal and child subscales ranged from $r=.92$ to $r=.62$, with a mean coefficient of .80 ; for anger, from $r=.86$ to $r=.60$, with a mean of .79 , and; for sadness, from $r=.94$ to $r=.70$, with a mean of .85. As we did not achieve acceptable interrater reliability on the Mother's Perception of Child Regulation, this subscale was removed from further analyses (reliability correlations for fear, anger, and sadness were $.58, .35$, and .64, respectively).

Complete interview data were obtained for 82 of the 90 mothers. Two interviews could not be coded because of technical difficulties, one for child fear and another for maternal fear, but scores on the other subscales were attained for both. Data were missing from the other six interviews for the following reasons: four could not be coded because of technical difficulties, one mother was very distressed by the interview questions and the interview was consequently aborted, and one interview was deemed invalid due to insufficient prompting by the interviewer.

\section{Results}

\section{AAI classification distribution}

Maternal AAI transcripts at 6 months were classified into one of the four adult attachment classifications (dismissing, preoccupied, autonomous, and unresolved). Of the 90 mothers 
participating in the study, $52(58 \%)$ received a primary classification of dismissing, $28(31 \%)$ of autonomous, and $10(11 \%)$ of preoccupied. Thirty $(33 \%)$ of these mothers were also classified as unresolved with respect to trauma or loss (18 dismissing, two autonomous, and all 10 preoccupied mothers).

A multivariate analysis of variance was used to determine whether mothers with different attachment representations (dismissing, autonomous, and unresolved) differed with respect to maternal education, personal income, household income, and maternal age at the time of the infant's birth. Seven subjects did not provide information about their personal income and 13 subjects did not provide information about their household income. In order to include the entire sample in the MANOVA, the missing values were estimated for these subjects. As suggested by Tabachnick and Fidell (1989), group means for the AAI classifications were calculated from the available data and were then used to replace the missing values for the income variables.

The multivariate test with the four dependent variables did not reach significance; however, the univariate and post hoc tests suggested that mothers differed on household income at 6 months, $F(2,87)=5.54, p<.05$, with dismissing mothers having a significantly higher household income than unresolved mothers $(p<.05)$. This variable was covaried out of all subsequent relevant analyses to ensure that the pattern of results was not unduly confounded by this variable. All multivariate effects continued to be significant with household income entered as a covariate and the pattern of univariate and pairwise effects remained.

\section{Meta-Emotion Interview: Variable reduction}

For purposes of parsimony and to increase the power of the analyses, aggregate variables were formed from the Meta-Emotion Interview (MEI) summary scores. In their 1996 study, Gottman and colleagues constructed a "coaching" score and an "awareness" score, summing across the different emotions and aggregating parental and child awareness scores. This approach, however, does not allow for the recognition of distinctive profiles of a mother's responses to fear, sadness, and anger, nor does it acknowledge the possibility of a mother's philosophy regarding her own emotions could be qualitatively different from her philosophy regarding her child's emotional experiences. In the current study correlations between analogous Maternal and Child MEI scale scores were actually relatively low, ranging from $r=.55$ (Awareness of Own Anger and Awareness of Child's Anger) to $r=.05$ (Acceptance of Own Fear and Acceptance of Child's Fear), with a mean correlation of .33. A series of analyses were performed to explore the relationships and distinctions among the various scales as a basis for the aggregation of the variables.

All 24 meta-emotion subscales were entered into a principal component analysis. Using the Eigenvalue $>1$ criterion for selecting factors, nine factors emerged. After Varimax rotation these factors accounted for $76.9 \%$ of the total variance. Subscales with loadings on a particular factor of $>.45$ were considered (Comrey, 1973). The factors that emerged appeared to represent dimensions that primarily described either a mother's philosophy of her own emotions or her philosophy relating to the emotions in her child, suggesting that maternal and child variables reflected distinct constructs. Additional data reduction, thus, was aimed at forming aggregate variables within these two areas.

A principal components analysis was completed with the 12 maternal meta-emotion interview variables. As indicated in Table I, five factors emerged, accounting for $74.35 \%$ of the total variance after Varimax rotation. Interpretive labels were loosely attached to the factors: awareness of internalizing affect, overall regulation, acceptance of internalizing affect, awareness of externalizing affect, and acceptance of externalizing affect. Our goal was 
Table I. Principal components analysis of maternal meta-emotion interview variables

\begin{tabular}{|c|c|c|c|}
\hline Factor & Percentage total variance & Subscales with loadings $>.40$ & Factor loadings \\
\hline \multirow{4}{*}{$\begin{array}{l}1 \text { Awareness of internalizing } \\
\text { affect (sadness/fear) }\end{array}$} & 19.56 & awareness of own fear* & -.46 \\
\hline & & $\begin{array}{l}\text { maternal fear \# “don't knows” } \\
(\mathrm{DKs})^{\star}\end{array}$ & .65 \\
\hline & & awareness of own sadness ${ }^{\star}$ & -.83 \\
\hline & & maternal sadness \# DKs* & .88 \\
\hline \multirow[t]{4}{*}{2 Overall regulation } & 16.03 & awareness of own fear & -.59 \\
\hline & & regulation of own fear ${ }^{\star}$ & .86 \\
\hline & & regulation of own anger ${ }^{\star}$ & .65 \\
\hline & & regulation of own sadness ${ }^{\star}$ & .41 \\
\hline \multirow{4}{*}{$\begin{array}{l}3 \text { Acceptance of internalizing } \\
\text { affect }\end{array}$} & 15.44 & awareness of own fear & .43 \\
\hline & & acceptance of own fear ${ }^{\star}$ & .74 \\
\hline & & acceptance of own sadness ${ }^{\star}$ & .76 \\
\hline & & regulation of own sadness & .58 \\
\hline \multirow{2}{*}{$\begin{array}{l}4 \text { Awareness of externalizing } \\
\text { affect (anger) }\end{array}$} & 13.69 & awareness of own anger ${ }^{\star}$ & -.82 \\
\hline & & maternal anger \# DKs* & .82 \\
\hline $\begin{array}{l}5 \text { Acceptance of externalizing } \\
\text { affect }\end{array}$ & 9.63 & acceptance of own anger ${ }^{\star}$ & .88 \\
\hline
\end{tabular}

to construct these aggregate variables such that they were both theoretically relevant and measured non-overlapping constructs. Thus, in a few instances, subscales that loaded $>.40$ on the factor were not included as part of the larger scale because they also loaded on another factor that was more theoretically relevant to the construct represented by that subscale. For example, "awareness of own fear" loaded on both the "Awareness of Internalizing Affect" (positive loading) and the "overall regulation" (negative loading) factors, probably because many mothers who described fear as dysregulating also tended to describe a hypervigilance to that emotion. We decided, however, to link it with the awareness scale for reasons of conceptual consistency ${ }^{2}$. Aggregate scales were formed by standardizing and then summing the individual scores that best described the factors. "Number of Don't Knows" were subtracted from the awareness scales. The maternal variables were generally only very moderately correlated, with an absolute mean intercorrelation of .18 , providing evidence that these variables are measuring relatively independent dimensions of maternal meta-emotion philosophy.

Aggregate scores were then formed from the 12 child variables in a similar fashion and these scores were entered into a principal components analysis. As shown in Table II, four factors emerged, accounting for $70.3 \%$ of the total variance after Varimax rotation. Considering those scales with factor loadings $>.40$ as significant, the first three factors quite neatly describe maternal attitudes toward the three emotions and thus were labeled accordingly: Response to Child's Fear (awareness, acceptance and coaching of fear), Response to Child's Sadness (awareness, acceptance and coaching of sadness), and Response to Child's Anger (acceptance and coaching of anger). The fourth factor that emerged in the PCA was not as easily interpreted (and was not identified as being a meaningful factor with the Scree plot criterion). Aggregate scales for the child variables, therefore, were based on only the first three factors.

Although the intervention was not designed to affect maternal meta-emotion functioning, the possibility that it had a direct or interactional impact on meta-emotion variables was 
Table II. Principal components analysis of child meta-emotion interview variables

\begin{tabular}{|c|c|c|c|}
\hline Factor & Percentage total variance & Subscales with loadings $>.40$ & Factor loadings \\
\hline \multirow[t]{3}{*}{ 1. Response to child's fear } & 21.32 & awareness of child's fear & .84 \\
\hline & & acceptance of child's fear & .81 \\
\hline & & coaching of child's fear & .90 \\
\hline \multirow{4}{*}{$\begin{array}{l}\text { 2. Response to child's } \\
\text { sadness }\end{array}$} & 19.57 & awareness of child's sadness & .85 \\
\hline & & acceptance of child's sadness & .40 \\
\hline & & coaching of child's sadness & .83 \\
\hline & & $\begin{array}{l}\text { child's sadness \# “don't knows' } \\
\text { (DKs) }\end{array}$ & $-.77^{\mathrm{a}}$ \\
\hline \multirow{2}{*}{ 3. Response to child's anger } & 14.88 & acceptance of child's anger & .89 \\
\hline & & coaching of child's anger & .85 \\
\hline \multirow[t]{4}{*}{ 4. (factor not interpreted) } & 14.52 & child's fear \# DKs & .76 \\
\hline & & awareness of child's anger & -.51 \\
\hline & & child's anger \# DKs & .68 \\
\hline & & acceptance of child's sadness & .41 \\
\hline
\end{tabular}

examined in 2-way multivariate analyses of variance (AAI classification by intervention group status), first using maternal MEI variables and then child MEI variables. This analysis indicated that mothers in the intervention group did not differ from mothers in the control group on either the maternal or the child MEI variables (both multivariate $p$ nonsignificant according to Wilk's Lambda criterion). Moreover, there were no significant interactions between AAI classifications and intervention group status on any of the dependent variables (both multivariate $p$ s nonsignificant). Thus, we were satisfied that the intervention did not moderate the relationship between attachment classification and maternal emotion variables nor have a direct impact on maternal emotional styles and self-reported responsiveness.

\section{Adult attachment representations and maternal emotions}

Mothers with different attachment representations were hypothesized to differ on their awareness, acceptance, and regulation of their own emotional states as assessed by the maternal scales of the MEI and the CES-D. No mothers in our study were classified with a primary preoccupied attachment representational status because the ten mothers who were classified as preoccupied were also unresolved with respect to loss or trauma. Thus, all of the following calculations were completed comparing the three attachment categories: dismissing, autonomous, and unresolved.

Differences between the different AAI classifications on the maternal MEI variables were assessed using a multivariate analysis of variance. The maternal Meta-Emotion Interview factors were entered as five dependent variables in a multivariate analysis of variance with dismissing, autonomous, and unresolved attachment classifications as three levels of the independent variables. The multivariate effect was significant using Wilk's Lambda criteria, $p<.01$. Subsequent univariate $F$ tests indicated that mothers differed on the domains of awareness of Internalizing Affect, Overall Regulation, and Awareness of Externalizing Affect. Post hoc tests showed that, dismissing mothers were significantly lower than autonomous mothers on Awareness of Internalizing Affect; unresolved mothers were significantly lower than autonomous mothers on Overall Regulation, and significantly higher than dismissing mothers on the domain of Awareness of Externalizing Affect (see Table III). 
Table III. Univariate tests for maternal MEI variables by AAI classifications.

\begin{tabular}{|c|c|c|c|c|c|c|c|}
\hline & \multicolumn{6}{|c|}{ Relationship classification } & \multirow[b]{3}{*}{$F$} \\
\hline & \multicolumn{2}{|c|}{ Dismissing (Ds) } & \multicolumn{2}{|c|}{ Autonomous (F) } & \multicolumn{2}{|c|}{ Unresolved (U/d) } & \\
\hline & M & SD & $M$ & SD & M & SD & \\
\hline \multicolumn{8}{|l|}{ MEI variables: } \\
\hline Awareness fear/sadness & -.986 & $(3.75)^{\mathrm{a}}$ & 1.09 & $(2.09)^{\mathrm{b}}$ & .129 & $(2.94)$ & $3.13^{\star}$ \\
\hline Overall regulation & .152 & $(2.52)$ & .869 & $(1.39)^{\mathrm{a}}$ & -.869 & $(2.32)^{\mathrm{b}}$ & $4.14^{\star}$ \\
\hline Acceptance fear/sadness & -.103 & $(1.70)$ & .568 & $(1.49)$ & -.379 & $(1.71)$ & 2.24 \\
\hline Awareness anger & -.605 & $(1.80)^{\mathrm{a}}$ & .194 & $(1.97)$ & .509 & $(1.34)^{\mathrm{b}}$ & $3.32^{\star}$ \\
\hline Acceptance anger & 3.17 & $(.335)$ & 3.23 & $(.287)$ & 3.09 & $(.351)$ & 1.25 \\
\hline
\end{tabular}

83 subjects were included in the MEI analysis ( $31 \mathrm{Ds}, 24 \mathrm{~F}, 28 \mathrm{U} / \mathrm{d}$ )

Means in the same row with different superscripts differ significantly at $p<.05$ with Tukey's post hoc statistic ${ }^{\star} p<.05$

An analysis of variance was completed to assess group differences (dismissing, autonomous, and unresolved) on self-reported depression as assessed with the CES-D. This univariate ANOVA with the CES-D scores as a dependent variable was significant, $F$ $(2,87)=7.9, p=.001$. Post hoc tests of means established that both dismissing and unresolved mothers had significantly higher levels of depression at 6 months than autonomous mothers.

Using this same data, chi square analyses revealed that AAI classifications were related to the probability of showing clinical levels of depression on the CES-D (scores greater than 16) at 6 months, $\chi^{2}(2, n=89)=9.52, p<.01$. As shown in Table IV, the proportions of dismissing, autonomous, and unresolved mothers reaching the clinical cutoff for depression at 6 months were $45 \%, 12 \%$, and $46 \%$, respectively.

\section{Externalizing versus internalizing symptoms of depression}

When both of the affective-internalizing and somatic-externalizing scales were entered into a MANOVA with the AAI classifications as levels of the independent variable, the multivariate effect was significant, $p<.001$, as were univariate effects for both the affective-internalizing and somatic-externalizing scales, $p<.01$. Post hoc tests revealed that unresolved mothers reported a significantly greater number of affective-internalizing symptoms than both dismissing and autonomous mothers, but dismissing mothers did not report a significantly greater number of these symptoms than autonomous mothers. Conversely, both dismissing and unresolved mothers reported a significantly greater number of somatic-externalizing symptoms than autonomous mothers (see Table $\mathrm{V}$ for group statistics and significance levels).

\section{AAI classifications and mindset relating to toddler emotions}

We also hypothesized that a mother's attachment representation would be systematically related to her attitudes and responses to emotions emerging in her toddler. That is, we expected that maternal responses to toddler emotions would reflect a mother's more general style of responding to and regulating her own emotions in a manner congruent with her attachment representation. 
Table IV. Differences between AAI categories on CES-D scores.

\begin{tabular}{|c|c|c|c|c|c|c|c|}
\hline & \multicolumn{6}{|c|}{ Relationship classification } & \\
\hline & \multicolumn{2}{|c|}{ Dismissing (Ds) } & \multicolumn{2}{|c|}{ Autonomous $(\mathrm{F})$} & \multicolumn{2}{|c|}{ Unresolved(U/d) } & \\
\hline & $M$ & $\mathrm{SD}$ & M & $\mathrm{SD}$ & $M$ & $\mathrm{SD}$ & \\
\hline \multicolumn{8}{|l|}{ CES-D scores } \\
\hline Clinical range $($ score $>16)$ & 15.09 & $(10.71)^{\mathrm{a}}$ & 8.65 & $(4.97)^{\mathrm{b}+}$ & 18.23 & $(9.93)^{\mathrm{a}+}$ & $F(2,87)=7 \cdot 90^{\star \star}$ \\
\hline $\begin{array}{l}\text { Number of subjects in } \\
\text { clinical range }\end{array}$ & 15 & $(45 \%)$ & 3 & $(12 \%)$ & 14 & $(46 \%)$ & $\chi^{2}(2, n=89)=9.52^{\star \star}$ \\
\hline $\begin{array}{l}\text { Number of subjects in sub- } \\
\text { clinical range }\end{array}$ & 18 & $(55 \%)$ & 23 & $(88 \%)$ & 16 & $(54 \%)$ & \\
\hline
\end{tabular}

89 subjects were included in the analysis (33 Ds, $26 \mathrm{~F}, 30 \mathrm{U} / \mathrm{d}$ )

Means in the same row with different superscripts differ significantly at $p<.05$ with Tukey's post hoc statistic.

Means in the same row sharing the superscript + differ at $p<.01$.

$\star \star p<.01$

Table V. A comparison of the AAI classifications on two subscales of the CES-D: Means, standard deviations, and test statistics.

\begin{tabular}{|c|c|c|c|c|c|c|c|}
\hline & \multicolumn{6}{|c|}{ Relationship classification } & \multirow[b]{4}{*}{$F(2,86)$} \\
\hline & \multirow{2}{*}{\multicolumn{2}{|c|}{$\begin{array}{c}\text { Dismissing (Ds) } \\
(n=33)\end{array}$}} & \multirow{2}{*}{\multicolumn{2}{|c|}{$\begin{array}{c}\text { Autonomous }(\mathrm{F}) \\
(n=26)\end{array}$}} & \multirow{2}{*}{\multicolumn{2}{|c|}{$\begin{array}{c}\text { Unresolved }(\mathrm{U} / \mathrm{d}) \\
(n=30)\end{array}$}} & \\
\hline & & & & & & & \\
\hline & M & SD & M & SD & M & SD & \\
\hline \multicolumn{8}{|l|}{ SCALE } \\
\hline Affective-Internalizing symptoms & 1.38 & $(.222)^{\mathrm{a}}$ & 1.33 & $(.161)^{\mathrm{a}+}$ & 1.54 & $(.260)^{\mathrm{b}+}$ & $7.19^{\star \star}$ \\
\hline Somatic-Externalizing symptoms & 0.68 & $(.600)^{a+}$ & 0.32 & $(.309)^{b+}$ & 0.83 & $(.517)^{\mathrm{a}}$ & $7.45^{\star \star}$ \\
\hline
\end{tabular}

Means in the same row with different superscripts differ significantly at $p<.05$ with Tukey's post hoc statistic. Means that also share the superscript + differ significantly at $p<.01$.

$\star \star p<.01$

Two separate MANOVAs were done with the three MEI aggregated factors (Response to Child's Fear, Response to Child's Anger, and Response to Child's Sadness) entered as dependent variables. The multivariate test was significant, Wilk's Lambda criteria, $p<.001$. All three univariate $F$-tests reached significance. Post hoc tests indicated that dismissing mothers had significantly lower scores than autonomous mothers on the subscales measuring their responsiveness to their children's fear and sadness. Moreover, unresolved mothers had significantly lower scores than autonomous mothers on the subscales measuring their responsiveness to their children's anger and sadness but not to fear (see Table VI).

\section{Discussion}

Relative to their non-autonomous counterparts, autonomous mothers saw themselves as more aware of and confident in their ability to regulate their emotions, as more open and responsive to their children's emotions, and as experiencing fewer depressive symptoms. 
Table VI. Univariate tests for child MEI subscales by AAI classifications.

\begin{tabular}{|c|c|c|c|c|c|c|c|}
\hline & \multicolumn{6}{|c|}{ Relationship classification } & \multirow[b]{4}{*}{$F(2,80)$} \\
\hline & \multirow{2}{*}{\multicolumn{2}{|c|}{$\begin{array}{c}\text { Dismissing (Ds) } \\
(n=32)\end{array}$}} & \multirow{2}{*}{\multicolumn{2}{|c|}{$\begin{array}{c}\text { Autonomous }(\mathrm{F}) \\
(n=23)\end{array}$}} & \multirow{2}{*}{\multicolumn{2}{|c|}{$\begin{array}{c}\text { Unresolved }(\mathrm{U} / \mathrm{d}) \\
(n=28)\end{array}$}} & \\
\hline & & & & & & & \\
\hline & $M$ & SD & M & SD & $M$ & SD & \\
\hline \multicolumn{8}{|l|}{ MEI variables: } \\
\hline Response to child's fear & -1.03 & $(2.86)^{+}$ & 1.44 & $(1.55)^{+}$ & 0.005 & $(2.54)$ & $6.70^{\star \star}$ \\
\hline Response to child's anger & 0.04 & $(1.73)$ & 1.02 & $(1.51)^{+}$ & -0.80 & $(1.77)^{+}$ & $7.35^{\star \star}$ \\
\hline Response to child's sadness & -0.29 & $(2.60)^{\mathrm{a}}$ & 1.24 & $(1.54)^{\mathrm{b}+}$ & -0.76 & $(2.23)^{+}$ & $5.52^{\star \star}$ \\
\hline
\end{tabular}

Means in the same row with different superscripts differ significantly at $p<.05$ with Tukey's post hoc statistic. Means in the same row with the superscript + differ significantly at $p<.01$.

$\star \star p<.01$

These findings support the expectation that an autonomous working model of relationships engenders a reflective and non-defensive approach to emotions and, thus, the capacity to remain well regulated when facing a wide range of affective experience. In contrast, dismissing mothers were less aware of their internalizing emotions and tended to talk about fear and sadness in a very defended fashion:

I don't really know 'cause I don't share my feelings. I just keep them bundled up and stuff...I don't like sharing my emotions at all. . I get really withdrawn. . But with my kid around it just kind of keeps things happy and joyful. She does things that make you kill yourself laughing.

Another dismissing mother responded to questions about fear:

...I'm not sure (nervous laugh)...I don't really think about it...If I think about it it gets worse. . so I just ignore it and it goes away.

A parent with such discomfort with her own emotions is likely to find it difficult to validate these same emotions in her child and will tend, in order to serve her own coping strategy, to minimize or distort her child's displays of negative emotions (Cassidy, 1994; Magai, 1999). Past research has suggested that dismissing mothers minimize, ignore, or respond negatively to their infants' negative affect (Dozier \& Kobak, 1992; Haft \& Slade, 1989; Zeanah et al., 1993); the current study provides critical new insight into the thoughts and feelings underlying this pattern and that prompt dismissing mothers to be less open and responsive to negative affect, particularly internalizing affect, than autonomous mothers. By way of illustration:

I don't know - I don't really know - sometimes, like, why she's sad. . what it is that's making her sad and so I'm kind of confused. Sometimes I don't know what to do because I'm totally confused. I don't know what she wants. I try a couple of things that doesn't work so. . It's frustrating ...

If a dismissing mother's attachment goals lead her to restrict her range of affect or cut herself off from her internal experiences, she is likely to find it difficult to identify, discriminate, and understand a full range of affect in her infant. Such difficulty, consistent with an avoidance strategy, is poignantly illustrated in the following: 
I don't really know why he's sad. But I don't really deal with it. . Like - I'll do the hugging and the "it's ok" and all that other kind of stuff but I don't...I try not to feel anything for anything. . .unless I have to. That's usually how I deal with it.

Such distinct discomfort with internalizing emotions including fear and sadness was much less apparent in dismissing mothers' discussions of externalizing emotions, such as anger. This observation is congruent with past research suggesting that dismissing individuals are likely to externalize negative affect (Kobak \& Sceery, 1988). From a functionalist perspective, anger may be conceived as a relatively empowering emotion because it can overturn obstacles that thwart one's goals (Campos, Mumme, Kermoian, \& Campos, 1994). In the relationship context, anger may sometimes serve the secondary function of disengaging or distancing oneself from interpersonal interactions. In accordance with such hypotheses, the higher levels of depression reported by dismissing mothers were associated with externalizing rather than internalizing symptoms.

The deactivating/externalizing emotional style of dismissing mothers appears, then, to come at a psychological cost. Dozier and Kobak (1992) found evidence that dismissing individuals exhibit heightened physiological arousal during affect-inducing segments of the AAI, even though their emotional expressions and discourse would suggest that they found the interview content neutral. This is analogous to the finding that avoidant infants often appear unaffected by their mothers' absence and reunion in the Strange Situation, even though physiological measures indicate that they find the situation stressful (Spangler \& Grossmann, 1993). It is possible, then, that dismissing individuals begin at a very young age to cut themselves off from internal state cues of distress in order to contain themselves in stressful situations with a rejecting caregiver and, thus, feel protected from their own sadness or anxiety. This separation of the underlying experience from the overt, conscious expression may become automatic and move out of conscious awareness over time. Dismissing mothers may ultimately come to experience the physiological symptoms of stress not as emotional signals but as discomfort arising from somatic or external sources.

\section{Emotional styles of preoccupied and unresolved mothers}

In contrast with their dismissing counterparts, we expected preoccupied mothers to exhibit a hyperactivating approach to emotions, amplifying affective experiences and expressions. Unfortunately, all mothers in this study who showed evidence of a preoccupied state of mind were also classified as unresolved with respect to loss and/or trauma and we were unable, therefore, to explore directly the emotional style of mothers with a uniquely preoccupied state of mind. It may be that an organized state of mind that relies on a hyperactivating emotional style cannot be sustained in the often chaotic and stressful life situations experienced by many young mothers. Oyen, Landy, \& Hilburn-Cobb (2000) have called for more focused research aimed at furthering our understanding of the behavior of preoccupied mothers in high risk sample, perhaps also allowing for a comparison of deactivating versus hyperactivating emotional styles in unresolved individuals.

In the current study we found evidence that unresolved mothers had difficulty regulating their own emotions and responding to emotions in their children. These mothers were significantly more likely to report internalizing and externalizing symptoms of depression. In short, unresolved mothers reported diminished emotion regulatory capacities that likely had a negative impact on their emotional well-being and their ability to respond comfortably and competently to their toddlers' emotions, for example: 
...before when I was aaah, sad and stuff like that before, when uh, I don't know maybe a couple of years ago when things were like really, really, really bad...the thought of suicide came... I would never do it, I mean I got so much to live for now, but I mean, just like when things seem so overwhelming. But now I've learned...like I said the other day when I was talking to someone about what happened a couple of days ago with my mom, and like, I get so mad and angry that, like my muscles tense up so bad that like, my, my calves and legs still hurt right now...

Unresolved mothers seemed to experience their emotions as out of their control, bleeding into one another, overwhelming and potentially dangerous, and displayed elevated levels of both internalizing and externalizing depressive symptoms. In sum, this study clearly suggests that unresolved young mothers experience significant difficulties with emotion regulation and that such difficulties leave them less capable than autonomous mothers of responding to their children's anger and sadness. To illustrate, when queried about her child's anger, an unresolved mother said:

...um, uncontrollable, like I feel like I, I, I've, I have no control over her sometimes when she's angry. Um, helpless, helpless, like I mean she's angry a lot of the time...

Child affective displays may trigger aspects of the mothers' own traumatic and unintegrated affective world (Lyons-Ruth et al., 1999; Main \& Hesse, 1990). A mother who experiences her own emotions as intense and potentially overwhelming must find it difficult to attune to and mirror her child's emotions and, thus, serve as an effective co-regulator of those emerging emotional experiences. Although unresolved mothers reported being less responsive to their children's anger and sadness, this was not true of fear. It is possible that some unresolved mothers received higher scores on the Responsiveness to Child's Fear scale because they expressed acute awareness of this emotion (which loaded on the responsiveness scale) but that they nevertheless experienced it as overwhelming. Unfortunately, because we did not achieve sufficient interrater reliability on the subscales measuring a mother's perception of her child' emotion regulation, we could not address this question directly.

The Meta-Emotion Interviews made it clear, however, that many unresolved mothers longed to be capable and sensitive caregivers with the ability to assuage their toddler's experiences of distress. Future interventions will be enhanced by research that assesses the extent to which these mothers have conscious control over their emotional responses in interaction with their children. Moreover, research on emotion socialization processes in samples of unresolved mothers will provide us with the basis for evaluating an alternative theoretical pathway for understanding the association between maternal unresolved attachment and infant disorganization (c.f., DeOliveira, Bailey, Moran, \& Pederson, 2004), building on the strong theoretical models existent in the literature (Lyons-Ruth et al., 1999; Main \& Hesse, 1990; Solomon \& George, 1999).

The current study establishes the Meta-Emotion Interview as a useful tool for broadening our understanding of the associations between attachment and emotional processing and development: the pattern of associations between a mother's personal affective style or mindset and her state of mind with regard to attachment was found to be consistent with theoretical predictions; moreover, these styles were concordant with mothers' reports of their sensitivity and responses to their child's emotions. These associations provide compelling empirical support for developmental framework linking the mother's past experiences, her representations of intimate relationships, her interactions with her child, 
and that child's own developing affective world. More research is needed, however, to help us understand the intergenerational effect of attachment on emotion socialization, especially among preoccupied mothers who are not unresolved with respect to loss or trauma. A broader focus of this sort will be possible in future research that considers the attachment and emotion narrative structure in samples of both high- and low-risk dyads and the wider familial context of the complex emotion developmental process.

\section{Acknowledgements}

This research was supported by a Doctoral Fellowship for the first author from the Social Sciences and Humanities Research Council of Canada, and by a Postdoctoral Fellowship for the first author from the Ontario Mental Health Foundation, and by research grants to the subsequent two authors from the Social Sciences and Humanities Research Council, Health Canada, and the Ontario Mental Health Foundation. Portions of this paper were presented at the 2001 Society for Research in Child Development Conference.

\section{Notes}

1 Mothers were also interviewed about their children's affection, but these responses were not coded for the purposes of the present study.

2 The only other two occasions in which a subscale with a high factor loading was not included on the scale were "awareness of own fear" and "regulation of own sadness", both of which loaded on the acceptance of internalizing emotions dimension.

\section{References}

Aber, J. L., Belsky, J., Slade, A., \& Crnic, K. (1999). Stability and change in mothers' representations of their relationships with their toddlers. Developmental Psychology, 35, 1038-1047.

Adam, E. K., Gunnar, M. R., \& Tanaka, A. (2004). Adult attachment, parent emotion, and observed parenting behavior: Mediator and moderator models. Child Development, 75, 110-122.

Allen, J. P., Hauser, S. T., \& Borman-Spurrel, E. (1996). Attachment theory as a framework for understanding the sequelae of severe adolescent psychopathology: An 11-year follow-up study. Fournal of Consulting and Clinical Psychology, 64, 254-263.

Berlin, L. J., \& Cassidy, J. (2003). Mothers' self-reported control of their preschool children's emotional expressiveness: A longitudinal study of association with infant-mother attachment and children's emotion regulation. Social Development, 12, $477-495$.

Bowlby, J. (1969/1982). Attachment and loss. Vol. 1: Attachment (2nd ed.). New York: Basic Books.

Campos, J. J., Mumme, D. L., Kermoian, R., \& Campos, R. G. (1994). A functionalist perspective on the nature of emotion. Monographs of the Society for Research in Child Development, 59, 284-303.

Comrey, A. L. (1973). A first course in factor analysis. New York: Academic Press.

Cassidy, J. (1994). Emotion regulation: Influences of attachment relationships. Monographs of the Society for Research in Child Development, 59, 228-249.

Cassidy, B., Zoccolillo, M., \& Hughes, S. (1996). Psychopathology in adolescent mothers and its effects on motherinfant interactions: A pilot study. Canadian fournal of Psychiatry, 41, 379-384.

Clark, G. N., \& Seifer, R. (1983). Facilitating mother-infant communication: A treatment model for high-risk and developmentally-delayed infants. Infant Mental Health fournal, 4, 67-81.

Cowan, P. A. (1996). Meta-thoughts on the role of meta-emotion in children's development: Comment on Gottman et al. (1996). Fournal of Family Psychology, 10, 277-283.

Creasey, G. (2002). Associations between working models of attachment and conflict management behavior in romantic couples. Fournal of Counseling Psychology, 49, 365-375.

DeOliveira, C. A., Bailey, H. N., Moran, G., \& Pederson, D. R. (2004). Emotion socialization as a framework for understanding the development of disorganized attachment. Social Development, 13, 437-467.

Dozier, M., \& Kobak, R. R. (1992). Psychophysiology in attachment interviews: Converging evidence for deactivating strategies. Child Development, 63, 1473-1480. 
Dozier, M., Stovall, K. C., \& Albus, K. E. (1999). Attachment and psychopathology in adulthood. In J. Cassidy \& P. R. Shaver (Eds.), Handbook of attachment: Theory, research, and clinical application (pp. 497 - 519). New York: Guilford.

Fonagy, P., Leith, T., Steele, M., Steele, H., Kennedy, R., Mattoon, G., Target, M., \& Gerber, A. (1996). The relation of attachment status, psychiatric classification, and response to psychotherapy. Fournal of Consulting and Clinical Psychology, 64, 22-31.

George, C., Kaplan, N., \& Main, M. (1996). Adult attachment interview. Unpublished interview, University of California, Berkeley.

George, C., \& Solomon, J. (1999). Attachment and caregiving: The caregiving behavioral system. In J. Cassidy \& P. R. Shaver (Eds.), Handbook of attachment (pp. 649-670). New York: Guilford.

Goldberg, S. (2000). Attachment and development. New York: Oxford University Press.

Goldberg, S., MacKay-Soroka, J., \& Rochester, J. (1994). Affect, attachment, and maternal responsiveness. Infant Behavior and Development, 17, 334-339.

Gottman, J. M., Katz, L. F., \& Hooven, C. (1996). Parental meta-emotion philosophy and the emotional life of families: Theoretical models and preliminary data. Fournal of Family Psychology, 10, $243-268$.

Grossmann, K. E., Grossmann, K., \& Schwan, A. (1986). Capturing the wider view of attachment: A reanalysis of Ainsworth's Strange Situation. In C. E. Izard \& P. B. Read (Eds.), Measuring emotions in infants and children, Vol. 2 (pp. 124-171). New York: Cambridge University Press.

Haft, W. L., \& Slade, A. (1989). Affect attunement and maternal attachment: A pilot study. Infant Mental Health fournal, 10, $157-172$.

Hesse, E., \& Main, M. (2000). Disorganized infant, child, and adult attachment: Collapse in the behavioural and attentional strategies. Fournal of the American Psychoanalytic Association, 48, 1097-1127.

Hooven, C. (1994). The meta-emotion coding system. Unpublished manuscript, University of Washington at Seattle.

Hooven, C., Gottman, J. M., \& Katz, L. F. (1995). Parental meta-emotion structure predicts family and child outcomes. Cognition and Emotion, 9, $229-264$.

Jacobvitz, D. B., Hazen, N. L., \& Riggs, S. (1997, April). Disorganized mental processes in mothers, frightening/ frightened caregiving, and disoriented, disorganized behaviour in infancy. In D. B. Jocobvitz (Chair), Caregiving correlates and longitudinal outcomes of disorganized attachments in infants. Symposium conducted at the biennial meeting of the Society for Research in Child Development, Washington, DC.

Katz, L. F., \& Gottman, J. M. (1986). The meta-emotion interview. Unpublished laboratory manual, University of Washington, Seattle.

Katz, L. F., Gottman, J. M., Shapiro, A. F., \& Carrere, S. (1997). The meta-emotion interview for parents of toddlers. Unpublished laboratory manual, University of Washington, Seattle.

Katz, L. F., \& Windecker-Nelson, B. (2001, April). Parent meta-emotion philosophy in families with conduct problem children. Paper presented at the Society for Research in Child Development, MN.

Kobak, R. R., \& Sceery, A. (1988). Attachment in late adolescence: Working models, affect regulations, and representations of self and others. Child Development, 59, 135-146.

Krupka, A. (1995). The quality of mother-infant interactions in families at risk for maladaptive parenting. Unpublished doctoral dissertation, University of Western Ontario, Canada.

Lyons-Ruth, K., Bronfman, E., \& Atwood, G. (1999). A relational diathesis model of hostile-helpless states of mind: Expressions in mother-infant interaction. In C. George \& J. Solomon (Eds.), Attachment disorganization (pp. 33-70). New York: Guilford.

Lyons-Ruth, K., \& Jacobvitz, D. (1999). Attachment disorganization: Unresolved loss, relational violence, and lapses in behavioral and attentional strategies. In J. Cassidy \& P. R. Shaver (Eds.), Handbook of attachment: Theory, research, and clinical applications (pp. 520-554). New York: Guilford.

Madigan, S., Moran, G., \& Pederson, D. R. (in press). Unresolved states of mind, disorganized attachment relationships, and disrupted mother-infant intentions of adolescent mothers and their infants. Developmental Psychology.

Magai, C. (1999). Affect, imagery, and attachment: Working models of interpersonal affect and the socialization of emotion. In J. Cassidy \& P. R. Shaver (Eds.), Handbook of attachment: Theory, research, and clinical application (pp. $787-802)$. New York: Guilford.

Main, M. (2000). The organized categories of infant, child, and adult attachment: Flexible vs. inflexible attention under attachment-related stress. Fournal of the American Psychoanalytic Association, 48, 1055-1096.

Main, M., \& Goldwyn, R. (1994/1998). Adult attachment classification system. Unpublished manual, University of California at Berkeley. 
Main, M., \& Hesse, E. (1990). Parents' unresolved traumatic experiences are related to infant disorganized attachment status: Is frightened and/or frightening parental behaviour the linking mechanism? In M. Greenberg, D. Cicchetti, \& E. M. Cummings (Eds.), Attachment in the preschool years: Theory, research, and intervention (pp. $161-184$ ). Chicago: University of Chicago Press.

Oyen, A. S., Landy, S., \& Hilburn-Cobb, C. (2000). Maternal attachment and sensitivity in an at-risk sample. Attachment and Human Development, 2, 203-217.

Radloff, L. S. (1977). The CES-D Scale: A self-report depression scale for research in the general population. Applied Psychological Measurement, 1, 385-401.

Riggs, S. A., \& Jacobvitz, D. (2002). Expectant parents' representations of early attachment relationships: Associations with mental health and family history. Fournal of Consulting and Clinical Psychology, 70, $195-204$.

Schuengel, C., Bakermans-Kranenburg, M. J., van IJzendoorn, M. H., \& Blom, M. (1999). Unresolved loss and infant disorganization: Links to frightening maternal behavior. In C. George \& J. Solomon (Eds.), Attachment Disorganization (pp. $71-94)$. New York: Guilford.

Slade, A., Belsky, J., Aber, J. L., \& Phelps, J. L. (1999). Mothers' representations of their relationships with their toddlers: Links to adult attachment and observed mothering. Developmental Psychology, 35, 611-619.

Solomon, J., \& George, C. (1999). The effects of attachment of overnight visitation in divorced and separated families: A longitudinal follow-up. In C. George \& J. Solomon (Eds.), Attachment Disorganization (pp. 243264). New York: Guilford.

Spangler, G., \& Grossmann, K. E. (1993). Biobehavioural organization in securely and insecurely attached infants. Child Development, 64, $1439-1450$.

Sroufe, L. A. (1996). Emotional development: The organization of emotional life in the early years. Cambridge: Cambridge University Press.

Statistics Canada (2001). Low income cutoffs from 1992 to 2001 and low income measures from 1991 to 2000. Retrieved August 27, 2004, from http://www.statcan.ca/english/research/75F0002MIE/75F0002MIE2002005.pdf

Tabachnick, B. G., \& Fidell, L. S. (1989). Using multivariate statistics (2nd ed.). NY: Harper Collins.

Thompson, R. A., Flood, M. F., \& Lundquist, L. (1995). Emotion regulation: It's relation to attachment and developmental psychopathology. In D. Cicchetti \& S.L. Toth (Eds.), Emotion, cognition, and representation: Rochester symposium on developmental psychopathology (pp. 261 -299). NY: University of Rochester Press.

True, M., Pisani, L., \& Oumar, F. (2001). Infant-mother attachment among the Dogon in Mali. Child Development, 75, 1451-1466.

van IJzendoorn, M. (1995). Adult attachment representations, parental responsiveness, and infant attachment: A meta-analysis on the predictive validity of the Adult Attachment Interview. Psychological Bulletin, 117, $387-403$.

Ward, M. J., \& Carlson, E. A. (1995). Associations among adult attachment representations, maternal sensitivity, and infant mother attachment in a sample of adolescent mothers. Child Development, 66, 69-79.

Zeanah, C. H., Beniot, D., Barton, M., Regan, C., Hirshberg, L. M., \& Lipsett, L. P. (1993). Representations of attachment in mothers and their one-year-old infants. Fournal of the American Academy of Child and Adolescent Psychiatry, 32, 278-286. 